\author{
EVS29 Symposium \\ Montréal, Québec, Canada, June 19-22, 2016
}

\title{
Drive Electric Vermont: EV Market Transformation in Small and Medium Sized Communities
}

\author{
David Roberts $^{1}$, Fred Wagner ${ }^{2}$, Jim Francfort ${ }^{3}$, Sera White ${ }^{3}$ \\ ${ }^{1}$ Vermont Energy Investment Corporation, 128 Lakeside Avenue, Burlington, VT 05401, droberts@veic.org \\ ${ }^{2}$ Energetics, 7067 Columbia Gateway Drive, Suite 200, Columbia, MD 21046 \\ ${ }^{3}$ Idaho National Laboratory, 2525 Fremont Avenue, Idaho Falls, ID 83415
}

\begin{abstract}
Summary
Investments in plug-in electric vehicles (PEVs) and charging infrastructure are often concentrated in large metropolitan areas. True market transformation to electric drive technologies will require moving beyond urban centers to include small and medium sized areas as well as rural communities. The Drive Electric Vermont (DEV) program was established in 2012 to shift consumers and businesses in Vermont (population $625,000)$ to greater awareness and use of PEVs. The US Department of Energy's EV Everywhere program recently completed a case study of DEV to document policy, marketing, and infrastructure development activities supporting increased use of PEVs outside of major metropolitan areas.
\end{abstract}

Keywords: EV, case-study, consortium, consumers, marketing

\section{Drive Electric Vermont Case Study Background}

Drive Electric Vermont (DEV) [1] was established in 2012 through an agreement between the State of Vermont and the non-profit Vermont Energy Investment Corporation (VEIC). VEIC leads DEV through coordination of stakeholder activities, sharing relevant data and information, and on-going outreach and program implementation. DEV stakeholders include representatives from electric utilities, automobile dealerships, regional planning organizations, state and local government, non-governmental organizations, and others supporting increased use of electric vehicles in Vermont.

The U.S. Department of Energy's (DOE) EV Everywhere Grand Challenge is identifying barriers and opportunities for enabling plugin electric vehicle (PEV) adoption. The DOE recognized the work of DEV and commissioned a case study [2] to identify the lessons learned and develop best practices for increasing PEVs and charging infrastructure deployment in small and midsize communities.

This paper summarizes the DEV Case Study with focus on aspects of the program which have worked most effectively in increasing awareness and adoption along with recognizing unique issues facing communities working to increase PEV use outside of major metropolitan areas. Detailed information on the case study findings is available in the final report, available on the Idaho National Laboratory's Advanced Vehicle Testing Activity website [3]. 


\section{Drive Electric Vermont Program Activities}

DEV is dedicated to boosting PEV adoption and guiding infrastructure growth by:

- Engaging Vermont consumers and businesses with outreach and advertising programs to increase awareness and purchase consideration of PEVs;

- Offering programs and incentives to help Vermonters purchase and charge their PEVs;

- Providing guidance on PEV charging infrastructure growth opportunities and best practices; and

- Serving as an objective third party resource providing information to a range of external constituents from consumers to businesses and local governments on buying and operating PEVs in Vermont.

\subsection{Policy}

DEV stakeholders gather quarterly to learn about new EV developments, share knowledge and coordinate PEV policy development in the state. The State of Vermont's Comprehensive Energy Plan (CEP) [4] provides a strong basis for PEV-supportive policies as the plan includes goals to reach $90 \%$ renewable energy use across all sectors by 2050. Increased use of PEVs and biofuels are key strategy recommendations in the CEP, which includes an interim goal to increase the share of renewable energy powering transportation to $10 \%$ by 2025 as part of a broader goal to reach $25 \%$ renewable energy use across all areas by 2025 .

DEV stakeholder policy discussions have covered incentives for PEV purchases, transportation user fee issues associated with lost fuel tax revenue, building code requirements for PEV charging infrastructure, funding and policy support for public charging infrastructure, and equity considerations associated with PEVs in disadvantaged communities.

\subsection{Infrastructure Development}

The majority of PEV charging activity occurs at home with workplaces comprising a much smaller, but still significant share [5]. Public charging accounts for a very small fraction of overall charging activity, but remains a critical issue for drivers considering a PEV, particularly All Electric Vehicles which do not have the ability to fall back to gasoline fuelled operation as plug-in hybrid electric vehicles can. Vermonters drive $20 \%$ more per capita than the national average [6] due to the state's rural character, so the development of a seamless network of public charging infrastructure across the state was identified as a priority early in the DEV program. Stakeholder partners worked to develop charging station installation guidance, perform outreach to potential hosts and provide funding for equipment and installation. As a result of this work, charging availability increased significantly over the past 3 years as shown in Figure 1 below.

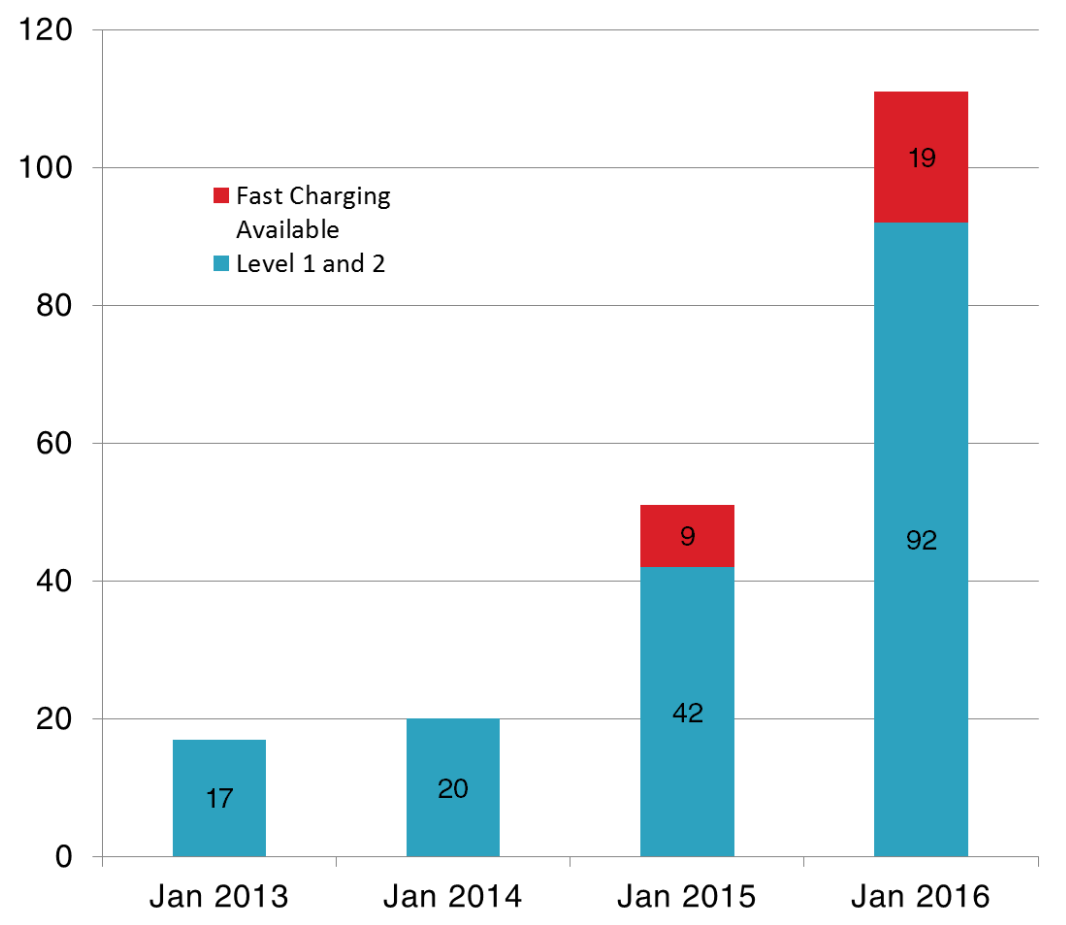

Figure 1: Total Vermont EVSE Locations [7] 
Electric utilities were instrumental in achieving this rate of growth over the past 4 years, particularly for the DC Fast Charging locations which can cost $\$ 20,000$ - \$50,000 per installation. Automotive Original Equipment Manufacturers (OEMs) also assisted in providing charging equipment. As of January 2016 approximately $90 \%$ of Vermont travel destinations (homes, workplaces, businesses, parks, etc) were within 20 miles of a PEV charging station and DEV stakeholders continue working toward closing remaining gaps in the network.

Workplace charging is recognized as an effective means of increasing adoption of PEVs, with research indicating employees with access to workplace charging are twenty times more likely to drive a PEV than those without access. As a result, DEV signed up to serve as an ambassador for the DOE EV Everywhere Workplace Charging Challenge to encourage employers to consider offering charging for employees [8].

The increasing visibility of PEV charging infrastructure is also helping to raise awareness of PEVs in the state as Vermonters see charging offered at business and high traffic locations across the state.

\subsection{Marketing and Outreach}

Marketing activities engaging with potential PEV consumers is necessary to achieve DEV's goals to increase use of PEVs in the state. DEV conducted a survey of Vermonters' attitudes and awareness of PEVs in 2014 [10] to support the creation of a detailed marketing plan based on local conditions. The survey identified key barriers for Vermonters considering a PEV, including purchase cost premiums, range concerns and operation in winter conditions. A strategic marketing campaign to build awareness and familiarity of EVs was designed in response to move consumers through the consumer decision funnel (Figure 2 below), shifting from simple awareness of PEVs toward greater consideration and purchasing. This required many engagements with potential consumers, including:

1. Website - development of an informational website as a resource for consumers, potential PEV charging hosts and policymakers. The DEV website had 18,000 unique visitors in 2015.

2. Events - ride \& drive events are proven to increase adoption of PEVs, particularly when consumers have an opportunity to get behind the wheel. DEV organized or participated in over 20 events reaching more than 4,000 people in 2015 .

3. Earned media - news reporting and Op-Eds featuring PEVs. News coverage has included Vermont, US national and Canadian outlets.

4. Dealer outreach - engaging with auto dealerships and industry representatives to provide PEV information and deliver incentives.

5. Advertising - Free advertising through the Google Grants program paired with paid web banner ads, such as the one shown in Figure 3 below.

6. Incentives - Monetary and non-monetary incentives are proven to increase PEV adoption [11] and the availability of incentives has been a primary topic of discussion among DEV stakeholders from the program inception. While no state funds have been available to support incentives to-date, DEV has worked with other partners to provide limited incentives in partnership with PEV dealerships.

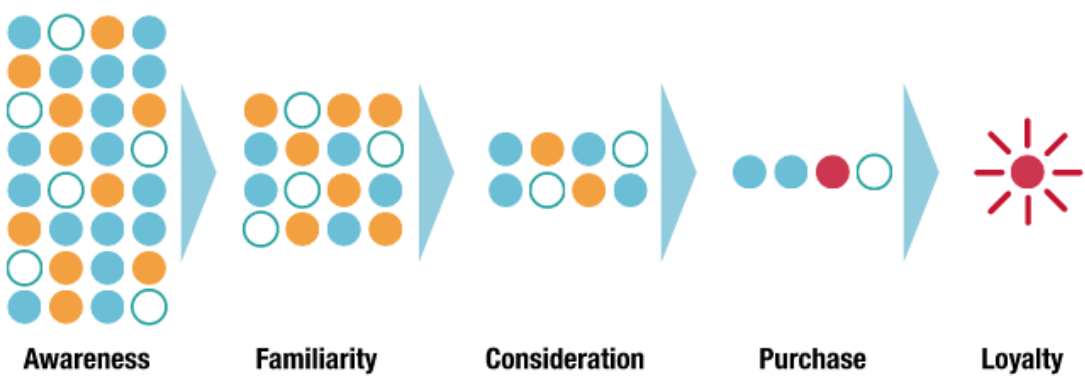

Figure 2: Consumer Decision Funnel [12] 


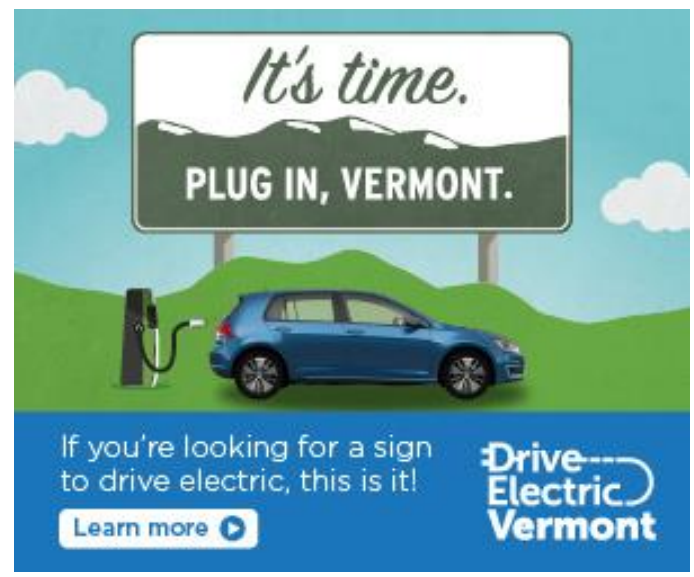

Figure 3: Example Drive Electric Vermont web advertisement

These programs have raised awareness of PEVs in the state and adoption continues to grow in response to marketing engagement as well as the general industry context of new and updated PEV models becoming available. Figure 4 below illustrates quarterly growth in PEV registrations since July 2012 when DEV started tracking this metric. As of January 2016, PEVs represented approximately 3\% of new light duty passenger car registrations and they can be found in over two-thirds of Vermont communities. The result being Vermont is tied with Detroit as having the highest percentage of PEV registrations in cold weather regions in the US [2].

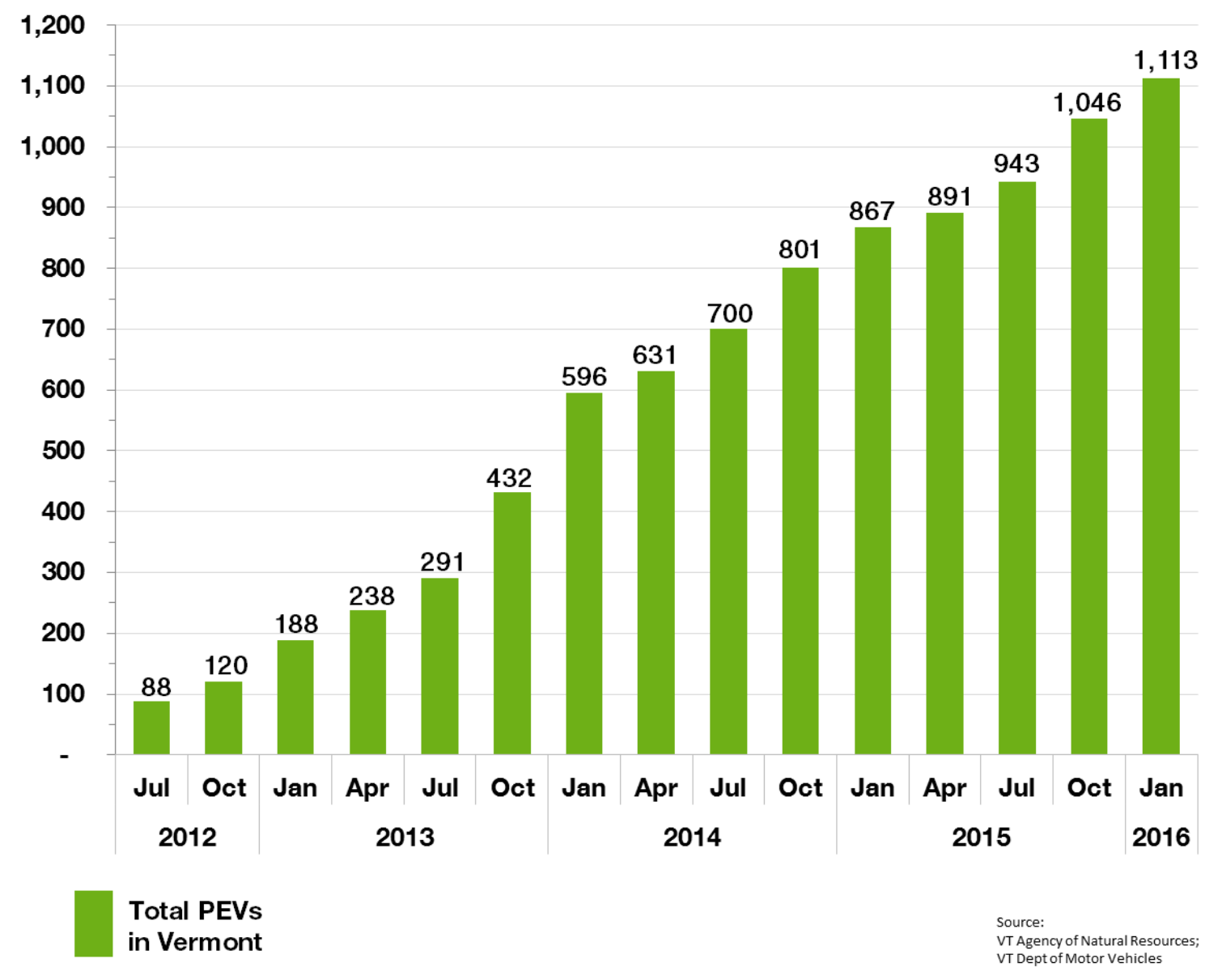

Figure 4: Vermont PEV Registrations, 2012-2016 


\section{Priority Recommendations}

The DEV case study report highlights several critical success factors many of which are broadly applicable to other small and medium sized communities considering how best to support PEV adoption. These include:

1. High level state and local policy support, including development of PEV-ready building codes to streamline future development of charging infrastructure

2. Providing a central hub and point of contact for PEV activities and information

3. Early and broad stakeholder involvement

4. Tracking PEV registration and related statistics to measure results

5. Education and coordination with auto dealers, particularly those enthusiastically embracing PEV sales

6. Coordination with electric utility providers on charging infrastructure development

7. Development of a "safety net" of PEV charging located approximately every 25 miles along heavily travelled corridors

8. Support for investing in vehicle incentives and infrastructure grants

9. Robust public outreach and education programs, including events, earned media placements and advertising as resources allow

10. Exploring partnerships with local Clean Cities Coalitions

11. Focusing marketing engagement to environmentally conscious populations

The PEV industry is rapidly transforming with the availability of new and updated PEVs, grid interactive charging capabilities, and autonomous vehicle technologies. Communities looking to support PEV adoption should keep abreast of current market conditions to ensure PEV program investments remain relevant. For example, PEVs with battery ranges over 200 miles may necessitate higher power DC Fast Charging equipment than the $25-50 \mathrm{~kW}$ units commonly used at present. Research activities investigating cost effective means of increasing PEV adoption will continue and provide additional guidance on shifting priorities in the future.

\section{Acknowledgements}

The authors wish to thank the US Department of Energy's EV Everywhere Grand Challenge and the Clean Cities Program and the Idaho National Lab's Advanced Vehicle Testing Activity for providing funding, resources, and assistance in the preparation of this case study.

\section{References}

[1] Drive Electric Vermont, http://www.DriveElectricVT.com, accessed on 2016-03-20

[2] Fred Wagner, et al., Drive Electric Vermont Case Study, INL/EXT-16-38077, Idaho National Laboratory, 2016

[3] Drive Electric Vermont Case Study, http://avt.inl.gov/pdf/evse/DriveElectricVermontCaseStudyMarch2016.pdf, accessed on 2016-03-24

[4] Vermont Comprehensive Energy Plan, http://publicservice.vermont.gov/publicationsresources/publications/energy_plan/2015_plan, accessed on 2016-03-20

[5] Plugged In: How Americans Charge Their Electric Vehicles, http://avt.inl.gov/pdf/arra/SummaryReport.pdf, accessed on 2016-03-23

[6] 2015 Vermont Transportation Energy Profile, http://vtrans.vermont.gov/sites/aot/files/VTTransportationEnergyProfile_2015_Final.pdf, accessed on 2016$03-23$

[7] US Dept of Energy Alternative Fuels Data Center: Alternative Fueling Station Locator, http://www.afdc.energy.gov/locator/stations/, accessed January annually

[8] EV Everywhere Workplace Charging Challenge, http://www.energy.gov/eere/vehicles/ev-everywhereworkplace-charging-challenge, accessed 2016-03-23

[9] Survey Says: Workplace Charging is Growing in Popularity and Impact, http://energy.gov/eere/articles/survey-says-workplace-charging-growing-popularity-and-impact, accessed 2016-03-23 
[10] A Survey of Electric Vehicle Awareness \& Preferences in Vermont, http://www.veic.org/resource-library/asurvey-of-electric-vehicle-awareness-preferences-in-vermont, accessed 2016-03-23

[11] Electric vehicle incentives, chargers, and sales, http://www.theicct.org/blogs/staff/ev-incentives-chargerssales, accessed 2016-03-23

[12] David Court, Dave Elzinga, Susan Mulder, and Ole Jørgen Vetvik. The Consumer Decision Journey, McKinsey Quarterly, June 2009.

\section{Authors}

David Roberts, Senior Consultant, VEIC, David Roberts is a VEIC Senior Consultant with more than 15 years' experience in outreach, planning and analysis that takes a systems approach to transportation efficiency research and program implementation taking into consideration the engineering, environmental and societal impacts associated with transportation energy use. He coordinates the Drive Electric Vermont partnership, a public-private stakeholder group working to increase adoption of electrified transportation in Vermont and has organized electric vehicle outreach events, developed charging station siting and installation guides, assessed financing mechanisms for vehicles and charging stations, and helped implement Vermont's first incentive program for plug-in vehicles in partnership with local auto dealerships. David holds a B.S. in Civil Engineering from the University of Virginia and a M.B.A. from the University of Vermont.

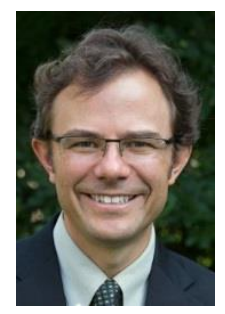

Fred Wagner, Program Manager, Energetics Incorporated, has provided technical and programmatic assistance to the U. S. Department of Energy's (DOE) Office of Energy Efficiency and Renewable Energy for 23 years. He has many years of consulting experience in electric drive, hybrid, heat engine, and fuel cell technologies; hydrogen and alternative fuels; and heavy truck systems optimization. Mr. Wagner provides support to the DOE Vehicle Technologies Office for RDD\&D program planning, alternative and advanced vehicle and infrastructure deployment, technical and economic feasibility assessment, and communications. He has provided support to the DOE Clean Cities Program for nearly 15 years. He has a M.S. in Engineering Management from the University of Maryland University College and a B.S. in Mechanical Engineering from the University of Maryland.

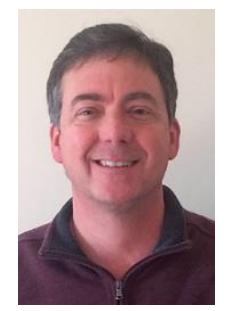

Jim Francfort has been the principle investigator for DOE's Advanced Vehicle Testing Activity (AVTA) at the Idaho National Laboratory (INL) since 1994. During this time, INL has collected operations and test data from 22,000 electric drive vehicles and 17,000 charging units in order to benchmark the petroleum reduction benefits of advanced technology vehicles and charging infrastructure. The 240 million test miles and 6 million charge events that INL has collected and analyzed, also serve to benchmark drivers' vehicle operations and recharging preferences. The technologies tested include more than 100 different vehicle models that range from advanced compressed hydrogen and natural gas vehicles to today's advanced plug-in electric vehicles. Jim has undergraduate and graduate degrees from Idaho State University, and more than 300 publications and presentations on vehicle testing and energy issues.

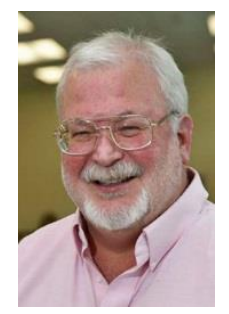


Sera White has worked with the INL Energy Storage and Transportation Department for nine years. She is currently leading the Advanced Transportation Computing Team. The computing team focuses on acquisition of large variable data sets, automated data processing, and producing information products and advanced visualizations. Prior to working within the Energy Storage and Transportation Department, Sera worked within the Idaho National Laboratory Geographic Information Systems group. Sera has a Bachelor of Science Degree in Computer Science and a Master of Science in Geographic Information Systems.

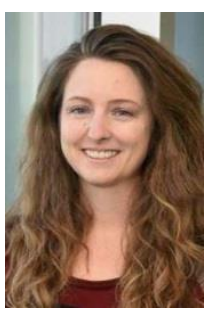

